\title{
Implantable Left Ventricular Assist Devices and the Kidney
}

\author{
Huijuan Mao ${ }^{a-c}$ Nevin Katz ${ }^{d}$ Jeong Chul Kimª, ${ }^{a}$ Sonya Day ${ }^{a, b}$ \\ Claudio Ronco ${ }^{\mathrm{a}, \mathrm{b}}$ \\ ${ }^{a}$ Department of Nephrology, Ospedale San Bortolo, ${ }^{b}$ International Renal Research Institute Vicenza (IRRIV), \\ Vicenza, Italy; ' ${ }^{C}$ Department of Nephrology, The First Affiliated Hospital of Nanjing Medical University, \\ Nanjing, China; d Department of Surgery, Johns Hopkins University, Baltimore, Md., USA
}

\section{Key Words}

Left ventricular assist devices $\cdot$ Kidney $\cdot$ Renal function

\begin{abstract}
The use of left ventricular assist devices (LVADs) in treating patients with advanced heart failure restores cardiac output resulting in improved perfusion to multiple organ systems with important clinical benefits. Renal pathophysiology during LVAD support remains an evolving, poorly understood, and potentially dynamic problem. Changes in renal function after LVAD placement have been investigated in multiple studies with contradictory results. Renal dysfunction is common prior to LVAD placement, which complicates postoperative clinical outcomes. The purpose of this review is to assess the latest information regarding the effects of LVADs on renal function with regard to hemodynamics, physiology, pathology and clinical issues prior to and after placement of the devices. The review should then aid in identifying patients best suited to benefit from this technology and to refine the therapy to reduce associated risks.

(c) 2014 S. Karger AG, Basel
\end{abstract}

\section{Introduction}

Nearly 5 million patients in the USA have heart failure (HF) and nearly 500,000 patients are diagnosed with HF for the first time each year [1]. Optimal medical therapy has included intravenous inotropes, vasodilators, intraaortic balloon pumps (IABP) and mechanical ventilation. Utilization of left ventricular assist devices (LVADs) has progressively increased for patients who fail to improve or stabilize with optimal medical management. The clinical approach to end-stage HF treatment then has been transformed into three pathways: (1) bridge to transplant (BTT), for patients who are transplant candidates but who will not survive waiting until an organ is available; (2) destination treatment, for patients who are not transplant candidates, and (3) bridge to recovery, for patients in whom the native heart function may possibly be recovered.

Over the past decade this device has been increasingly used as a destination therapy with thousands of patients having benefitted from LVAD support for 2 years or more. Therapeutic LVAD implementation both as a bridge to cardiac transplantation and as a destination therapy in patients with advanced HF has been shown to increase cardiac output and restore perfusion to multiple organs, providing beneficial peripheral circulation for months to years. The use of LVADs in patients with advanced $H F$ has resulted in improved survival, functional capacity, and quality of life $[2,3]$.

A patient's renal function is an especially important consideration in the decision regarding placement of an LVAD. Renal dysfunction (RD) is frequent in chronic congestive HF patients which can complicate patient out-

\section{KARGER}

E-Mail karger@karger.com

www.karger.com/bpu
(C) 2014 S. Karger AG, Basel

0253-5068/14/0371-0057\$39.50/0
Claudio Ronco

Department of Nephrology

San Bortolo Hospital

Viale Rodolfi 37, I-36100 Vicenza (Italy)

E-Mail cronco@goldnet.it 
comes after LVAD placement $[4,5]$. In addition, cardiac transplant recipients are at increased risk for renal impairment. Renal pathophysiology during LVAD support remains an evolving, poorly understood, and potentially dynamic problem. Changes in renal function after LVAD implementation have been explored in multiple studies with contradictory results. Some studies indicate that patients with RD have worse outcomes after LVAD implantation although kidney function has been shown to stabilize and improve [6-9]. Other studies have demonstrated increasing kidney dysfunction leading to renal replacement therapy (RRT) transiently or chronic dialysis [1012]. Identification of patient parameters that predict accurately outcomes with LVAD implantation is essential for optimal selection of therapeutic options and reducing postoperative risk.

Severe RD (need for hemodialysis or serum creatinine $(\mathrm{sCr})>2.5-3 \mathrm{mg} / \mathrm{dl}$ deemed irreversible) is considered a relative contraindication for LVAD implantation [13, 14]. It is also possible that improved hemodynamic status and corrected neurohormonal dysregulation $[4,15]$ may improve renal function and contribute to prolonged survival [16]. The relationship between renal function and LVAD is complex. RD prior to implantation is not necessarily a strong predictor of acute renal failure (ARF) after LVAD implantation $[8,9,16]$. The reversibility of $\mathrm{RD}$ in the cardiorenal syndrome is a major issue in patients being considered for heart transplantation. How to predict irreversible RD during LVAD support and how to determine which patients are best suited for LVAD implantation are critical and formidable clinical issues $[4,5]$. The authors review renal effects of LVAD in terms of hemodynamics, physiology, pathology and clinical issues prior to and after placement of devices to aid in identifying patients best suited to benefit from this technology and to refine the therapy to reduce associated risks.

\section{LVAD Categorization and Mechanism}

The basic support mechanism of a ventricular assist device (VAD) is to provide pressure and volume unloading of the heart by means of mechanical circulatory support. LVAD is the most common type of VAD, assisting the left ventricular function by draining blood from the left side of the heart and pumping blood directly into the aorta. For optimal performance, LVAD devices require pump flow rates of 3-8 $1 / \mathrm{min}$ and a pressure differential of $80-100 \mathrm{~mm} \mathrm{Hg}$. An LVAD system, generally, consists of cannulas, blood pump, controller, percutaneous leads and an external power source. The drainage cannula which provides inflow to the pump is connected to the apex of the left ventricle and the outflow cannula is anastomosed to the proximal ascending aorta. Blood withdrawn from the left ventricle enters the LVAD pump and returns via outflow cannula into the proximal ascending aorta, carrying blood into the systemic circulation. LVADs are implanted either pre- or intraperitoneally. Smaller pumps that can be implanted adjacent to the heart in the chest cavity are under development [17].

The most critical functional unit of an LVAD is the blood pump. LVAD blood pumps are classified as pulsatile or continuous. Development of pulsatile LVAD such as Novacor N1000PC (World Heart, Inc., Oakland, Calif., USA) and HeartMate VE (Thoratec Laboratories Corp., Pleasanton, Calif., USA) systems were previously popular due to the view that the pulsatile flow similar to the natural pulsing action of the heart would be beneficial. The pulsatile flow of these devices was generated by pneumatic mechanisms or pusher plate displacement emptying conduits filled with blood through one-way valves at a rate of $80-100$ beats/min. However, the complex mechanisms requiring large consoles for power supply and the limited use of these devices in patients with a body surface area $>1.5 \mathrm{~m}^{2}$ [18] led to the continued expansion of flow pump technology. The smaller sizes of continuous-flow pumps and their increased reliability led to the progressive increase in their clinical use [3].

Recent devices such as HeartMate II (formerly Nimbus) (Thoratec Laboratories Corp.), MicroMed DeBakey VAD (MicroMed Cardiovascular, Inc., Tex., USA), Berlin Heart INCOR (Berlin Heart GmbH, Germany) and Jarvik 2000 Flow Maker (Jarvik Heart, Inc., N.Y., USA) systems adopt axial flow for the pump mechanism. Some of the recent continuous-flow LVADs, such as DuraHeart (Terumo Heart, Inc., Mich., USA), VentrAssist (Ventracor, N.S.W., Australia), CorAide (Arrow International, Pa., USA), HeartWare HVAD (HeartWare, Inc., Mass., USA) and Levacor (World Heart, Inc., Calif., USA) systems employ centrifugal pump systems [19].

Continuous-flow pumps currently account for more than $98 \%$ of adult primary LVAD implantations in the USA. Axial- or centrifugal-flow pumps basically provide continuous, nonphasic blood flow and consist of an electromagnetically actuated impeller containing curved blades that spin in a magnetic field reducing blood-surface contact. A drawback of this system is that continuous anticoagulation therapy with either warfarin or aspirin is necessary to prevent emboli and/or pump thrombosis and the system works at very high rotational speeds 
around 8,000-10,000 rpm leading to heat generation and a higher risk of hemolysis. Additionally, the flow they provide is nonpulsatile and this nonphysiological condition, although well tolerated by mammalian organisms after a period of adaptation [20], may cause compromises and distorting effects in vascular activity $[21,22]$, baroreceptor activity, catecholamine release, lymphatic pump, renal cortical blood flow, fluid shift and vascular wall structure integrity in the early period after implantation [19].

\section{Renal Hemodynamics and Physiological, Pathological Change}

The improvement of renal function by LVAD implantation seems to be mediated not only by improvement of hemodynamics, but also by reduction of deleterious nonhemodynamic factors, such as sympathetic overactivity $[23,24]$, overactivity of the renin-angiotensin-aldosterone system (RAAS) [4, 23, 25], and inactivation of nitric oxide [26], factors which are known to be responsible for $\mathrm{RD}$ in $\mathrm{HF}$ [27].

\section{Improvement of Renal Blood Redistribution}

During cardiogenic shock or low cardiac output, renal arterial blood flow, mainly cortical blood flow, decreases when perfusion pressure is below a critical level, resulting in redistribution of renal blood flow. Sezai et al. [28] found that renal cortical blood flow increased but medulla blood flow decreased with the support of a pulsatile LVAD in an acute myocardial infarction model of pigs. Nemoto [29] compared the effect of pulsatile and nonpulsatile VAD on renal circulation and compared the differences between pigs supported by high-level (assist rate of $80 \%$ ) and low-level (assist rate of 60\%) artificial circulation under a cardiogenic shock condition. With VAD support, redistribution of renal blood flow and tissue metabolism were improved in different degrees, however renal arterial blood flow, renal cortical/medullar blood flow ratios and renal cortical tissue blood flow were all apparently superior with a pulsatile VAD versus a nonpulsatile VAD, particularly when supported by low-level assist artificial circulation. This suggested that when a nonpulsatile VAD is used in cardiac shock, better results could be obtained if a sufficient blood flow, at least $80 \%$ or a higher level of aortic blood flow, is maintained.

Recently, Iwashima et al. [30] investigated intrarenal blood flow in patients supported with pulsatile LVAD using duplex Doppler sonography. This support was accompanied by significantly improved renal function, de- creased mean peak systolic velocity $(38.2 \pm 8.9$ to $28.3 \pm$ $2.2 \mathrm{~cm} / \mathrm{s}, \mathrm{p}<0.05)$ and increased mean end-diastolic velocity $(8.3 \pm 3.2$ to $11.3 \pm 1.3 \mathrm{~cm} / \mathrm{s}, \mathrm{p}<0.05)$, and thus significantly improved mean renal resistive index $(0.79 \pm$ 0.06 to $0.60 \pm 0.04, \mathrm{p}<0.01)$. The improved renal function may be mediated in part through an improvement of intrarenal hemodynamics.

\section{Alleviation of RAAS Activation}

Animal studies employing healthy heart models have shown substantially elevated plasma renin levels $(\mathrm{pg} / \mathrm{ml})$ from $1.4 \pm 0.3$ to $2.9 \pm 0.3(\mathrm{p}<0.05)$ with nonpulsatile LVAD, but without a significant rise in blood pressure [25]. Additional studies indicated upregulation of the local RAAS of the inflammatory cells in periarterial areas of the kidney by continuous-flow LVAD [31]. However, in patients awaiting cardiac transplant, after $86 \pm 40$ days LVAD support, both plasma renin activity $(\mathrm{ng} / \mathrm{ml} / \mathrm{h})$ and angiotensin II level (U/l) decreased ( $57 \pm 56$ to $3 \pm 3$, mean change of $92 \%, p<0.001 ; 237 \pm 398$ to $14 \pm 14$, mean change of $73 \%, p<0.001$, respectively) from baseline (before implantation) to at explant/transplantation. This suggests that the RAAS activation in HF is importantly reduced after LVAD implantation, providing biochemical confirmation of the improvement in hemodynamic status [23]. James et al. [15] also found that in BTT patients, plasma renin activity and plasma aldosterone decreased significantly from baseline to week 4 , and to week 8 after implantation of LVAD. Furthermore, the reduction of RAAS activity occurred earlier than the reduction of plasma volume and plasma atrial natriuretic peptide level, suggesting the improvement of cardiac function by LVAD was associated with normalization of volume load secondary to normalization of its regulatory substances.

\section{Mitigation of Sympathetic Activation}

LVAD assistance in healthy dogs has produced favorable hemodynamic changes, such as a decrease in left atrial pressure, in parallel with the decrease of sympathetic tone, monitored by detection of renal sympathetic nerve activity. This renal sympathetic nerve activity may be mediated by the aortic and cardiopulmonary baroreflex system and may lead to a decrease in renal vascular resistance $[24,32,33]$. In a cardiac arrest model, under the condition of circulation maintenance with LVAD, coherence at the cardiac rhythm frequency was decreased and coherence at the LVAD pumping rhythm frequency was increased [34, 35].

In BTT patients, LVAD support was associated with plasma epinephrine $(\mathrm{pg} / \mathrm{ml})$ levels being decreased from 
$6,800 \pm 1,323$ to $46 \pm 46$ (mean change $86 \%, \mathrm{p}<0.001$ ) and plasma norepinephrine $(\mathrm{pg} / \mathrm{ml})$ being decreased from $2,953 \pm 1,457$ to $518 \pm 290$ (mean change of $79 \%$, $p<$ $0.001)[23]$.

\section{Pathological Change in Animal Experiment}

Nishimura et al. [36] described wall thickness of the aortic wall becoming thinner with long-term continuous flow of LVAD, possibly caused by decreased mechanical stress. In a healthy sheep model, an implanted nonpulsatile LVAD was associated with thinning of the medial layer of the ascending aorta, but with no histologic change in the kidney [25].

Kihara et al. [37] found medial smooth muscle cell hypertrophy of renal cortex arteries and inflammatory cell infiltration of the arteries' walls and the surrounding interstitium with chronic continuous-flow LVAD and a trend toward increased hypertrophy with lower flow rates. Ootaki et al. [31] showed severe periarteritis with smooth muscle layer hyperplasia in the kidneys of healthy calves with continuous-flow LVAD. The mechanism of this altered morphology was unclear. The change in local RAAS activation secondary to decreased renal arterial pressure pulsatility may be the primary factor leading to these pathological findings.

In a healthy dog model with LVAD support, immunohistological examination of renal tissues demonstrated an accumulation of NF- $\kappa B$, TNF- $\alpha$ and IL- $1 \beta$, indicating that for optimal LVAD support, appropriate timing is essential to avoid secondary inflammation induced by LVAD implantation [38].

\section{Effect of Baseline Renal Function on Outcome after LVAD}

\section{Effect of Baseline Renal Function on Survival}

The preoperative risk factors for LVAD implantation and their impact on the clinical outcome should be analyzed to evaluate the optimal timing of LVAD implantation for severe HF patients. The early mortality, the recovery and complications are all more likely to depend on preoperative status than the type of device used [39, 40]. There is no dispute that the INTERMACS classification system serves as a useful metric for risk-stratifying candidates for LVAD [41, 42]. Yoshioka et al. [39] demonstrated that the cumulative survival rate was significantly different between the INTERMACS level 1 group and the level $2 / 3$ group: 82.9 vs. $100 \%$ for 30 days, 75.6 vs. $97.7 \%$ for 90 days, and 63.7 vs. $85.3 \%$ (all $p=0.015)$ for 1 year after LVAD implantation. Using multivariate analysis for the INTERMACS level 1 group data, Yoshioka et al. [39] found that the preoperative $\mathrm{sCr}$ level was the independent predictor of 90-day mortality $(\mathrm{p}=0.003)$ and a preoperative level of sCr of $1.96 \mathrm{mg} / \mathrm{dl}$ was an optimal cut-off value for 90-day mortality. Importantly, these results indicate the advantage of LVAD implantation prior to deterioration of renal function when critical cardiogenic shock occurs. Butler et al. [9] compared post-LVAD outcomes in 220 patients, who were divided into four groups based on basal $\mathrm{CrCl}(\mathrm{ml} / \mathrm{min})$ quartiles: <47, 48-68, 69-95, and $>95$. Patients in the lowest $\mathrm{CrCl}$ quartile were at a higher risk of dying postimplant (OR 1.95, 95\% CI 1.14-3.63) and survival followed the renal function by quartiles on LVAD: $42,52,63$, and $79 \%$ for 6 months, and 26, 34, 47, and $66 \%$ for 12 -month survival for quartiles 1-4 (both $\mathrm{p}<$ 0.01 for the trend). Sandner et al. [16] also found that post-LVAD survival at 1,3 , and 6 months for glomerular filtration rate (GFR) $\left(>60 \mathrm{ml} / \mathrm{min} / 1.73 \mathrm{~m}^{2}\right)$ was $91.3,79.9$, and $72.6 \%$, respectively, while for GFR $<60 \mathrm{ml} / \mathrm{min} / 1.73 \mathrm{~m}^{2}$ it was $92.5,66.5$, and $47.9 \%$, respectively $(p=0.038)$. These results suggest that LVAD implantation should be considered without delay for patients with end-stage HF if renal function progressively declines despite optimal medical therapy.

On the other hand, post-LVAD survival is more likely related to the improvement of renal function after LVAD support than to the basal preoperation renal function. Sandner et al. [16] found that survival was improved in patients with GFR $<60 \mathrm{ml} \cdot \mathrm{min} / 1.73 \mathrm{~m}^{2}$ who after LVAD implantation recovered renal function to GFR $>60$ ( $\mathrm{p}<$ 0.001 ). Butler et al. [9] also showed that recovery of renal function to creatinine clearances $(\mathrm{CrCl})>50 \mathrm{ml} / \mathrm{min}$ was associated with a trend towards better 30-day survival. Furthermore, Singh et al. [43] concluded that patients who had a $\mathrm{CrCl}>60 \mathrm{ml} / \mathrm{min}$ before cardiac transplantation (CTX) had a similar 1-year posttransplant $\mathrm{CrCl}$, regardless of renal function before LVAD support. However, the ability to achieve this level of renal function after VAD was less likely in those with the worst renal function before the initiation of VAD. All these studies indicated that the survival after VAD support and the renal outcomes after CTX seemed to be more dependent on the level of renal function achieved during VAD than on the basal renal function before VAD. RD is the most common modifiable contraindication to CTX in LVAD support patients [44]. LVAD support before CTX may help differentiate between reversible and nonreversible RD [6]. Severe RD complicating cardiogenic shock was not always a contraindication to LVAD as a bridge to CTX [45]. Khot et al. [45] surveyed
Mao/Katz/Kim/Day/Ronco 
patients with $\mathrm{sCr} \geq 3.0(4.0 \pm 0.7) \mathrm{mg} / \mathrm{dl}$ at the time of $\mathrm{VAD}$ placement and found similar outcomes compared to patients without severe $\mathrm{RD}$, with respect to overall 30-day and 6-month survival after VAD placement, survival to transplantation ( 61 vs. $68 \%, \mathrm{p}=0.549$ ) and survival 1 year posttransplantation ( 82 vs. $88 \%, \mathrm{p}=0.628$ ).

\section{Effect of Baseline Renal Function on Renal Recovery,}

ICU Stay and BTT

Moderate to severe RD, defined by a GFR $<60 \mathrm{ml} /$ $\min / 1.73 \mathrm{~m}^{2}$, has been documented in $64 \%$ of patients hospitalized for decompensated HF [46]. In patients with New York Heart Association (NYHA) class IV symptoms or with NYHA class III symptoms, 39 and $31 \%$ had $\mathrm{CrCl}$ $<30 \mathrm{ml} / \mathrm{min}$, respectively [47]. Compared with patients with HF without RD, patients with RD experienced higher morbidity and mortality $[9,48]$. In the study of Ma et al. [40], a statistically significant correlation between preoperative $\mathrm{sCr}$ and days until the patient's $\mathrm{sCr}$ dropped below $1.5 \mathrm{mg} / \mathrm{dl}$ was found $(\mathrm{AUC}=0.793, \mathrm{p}=0.018$ ) and the best cut-off value of preoperative sCr level for predicting an ICU stay more than 30 days was $1.95 \mathrm{mg} / \mathrm{dl}$. In addition, the BTT rate was lower for GFR $<60$ than for GFR $>60 \mathrm{ml} / \mathrm{min} / 1.73 \mathrm{~m}^{2}$ (40.0 vs. $63.0 \%, \mathrm{p}=0.033$ ) [16]. Singh et al. [43] investigated the impact of pre-VAD RD on renal function after CTX. In this study, patients were grouped according to tertiles of pre- $\mathrm{VAD} \mathrm{CrCl}$ and the mean duration of VAD was 124 days. The results showed that patients in the group with $\mathrm{CrCl}>65$ had the best renal outcomes both after VAD and 1 year after CTX.

\section{Changes in Renal Function after LVAD}

The pathophysiologic interaction of cardiac and renal disorders is complex. The change of renal function after LVAD has been explored in multiple studies with contradictory results. A minority of patients experience an unfavorable postimplantation course. The majority of patients have improved renal function with LVAD support. Renal function improves substantially and rapidly in post-LVAD survivors and is associated with improved outcomes. For most patients, LVAD support optimizes circulation and improves renal function. Recovery of renal function after implantation of LVAD has been investigated in different cohorts (table 1) [6-9, 16, 43, 49], including with basal modest RD and with pulsatile, axialflow centrifugal devices implanted [8, 49]. However, no further improvement in renal function was observed after 1 month $[8,43]$. The lack of further improvement may represent the patient's underlying level of intrinsic RD related to diabetes, hypertension, renovascular disease, or irreversible renal injury from the HF state. These results indicated that in most patients with end-stage HF considered for LVAD implantation, RD was reversible and likely related to poor renal perfusion.

\section{Predictive Factors of Reversibility of Renal \\ Dysfunction}

Renal damage may persist despite general clinical improvement. It remains difficult to predict which patients will benefit most from LVAD implantation. Imamura et al. [50] reported that a risk scoring system consisting of the preoperative Scr level adjusted by the patient's age could predict the reversibility of RD with LVAD implantation in a single center. Currently used predictors include careful assessment of right ventricular function as well as various risk scores, some of which are outdated or not validated for the current population [13]. Temporary end-organ improvement under monitored treatment may be a novel way for predicting postoperative outcomes. In the study of Hasin et al. [6], younger age, GFR improvement with optimal medical therapy, IABP use, kidney length $>10 \mathrm{~cm}$, no treatment with angiotensinconverting enzyme inhibitors or angiotensin receptor blockers, higher bilirubin, higher Lietz-Miller score, and atrial fibrillation were univariate preoperative predictors for improvement in renal function at 1 month. Further multivariate analysis indicated preoperatively improved GFR and IABP use as independent predictors. The positive predictors may represent stronger cardiac-derived cardiorenal syndrome (type 2), while the negative predictors (small kidney, older age) represent more renal-derived (type 4) cardiorenal syndrome [6]. Accurate, early assessment of renal function is essential to determine whether renal impairment stems from primary renal disease or poor perfusion.

\section{Incidence, Risk Factors and Outcome of Acute Kidney} Injury after LVAD Support

Acute kidney injury (AKI), a common sequel of LVAD implantation in patients with end-stage HF, is evident in the first few days postimplantation $[12,51]$ and is associated with poor outcomes $[10,52,53]$. The development of AKI may result from an unfavorable early postoperative course and early hemodynamic instability [10]. The incidence of postimplantation AKI has been reported in a wide range from 14 to $45 \%$, according to different diagnosis criteria and different clinical conditions (table 2), but was comparable between continuous- 
Table 1. Improved renal function after LVAD implantation

\begin{tabular}{|c|c|c|c|c|c|c|c|}
\hline $\begin{array}{l}\text { Reference } \\
\text { (first author) }\end{array}$ & LVAD type & \multicolumn{5}{|c|}{ Change of renal function } & Others \\
\hline Russell [7] & continuous & $\begin{array}{l}\text { above-normal group: } \\
\mathrm{BUN}^{3} 37 \pm 14 \\
\mathrm{sCr}^{4} 1.8 \pm 0.4\end{array}$ & & & & $\begin{array}{l}\text { BUN } \\
23 \pm 10 \\
\text { sCr } 1.4 \pm 0.8\end{array}$ & $\begin{array}{l}\text { values in the normal group } \\
\text { remain in the normal range } \\
\text { over time }\end{array}$ \\
\hline Sandner [8] & $\begin{array}{l}\text { continuous } \\
(\mathrm{C}) \text { and } \\
\text { pulsatile }(\mathrm{P})\end{array}$ & $\begin{array}{l}\mathrm{eGFR}^{2} \\
\mathrm{C}: 59.4 \pm 22.8 \\
\text { P: } 52.5 \pm 21.1\end{array}$ & $\begin{array}{l}\text { C: } 76.4 \pm 38.6 \\
\text { P: } 69.2 \pm 34.7\end{array}$ & $\begin{array}{l}\text { C: } 84.3 \pm 32.9 \\
P: 79.9 \pm 38.7\end{array}$ & $\begin{array}{l}\text { C: } 75.3 \pm 30.2 \\
\text { P: } 74.2 \pm 27.2\end{array}$ & & $\begin{array}{l}\text { continuous- and pulsatile-flow } \\
\text { device had comparable effect } \\
\text { on } \mathrm{RF}^{1}\end{array}$ \\
\hline Butler [9] & pulsatile & $\begin{array}{l}\mathrm{CrCl}^{5}: 77.0 \pm 46.6 \\
\text { pre-CrCl }<50 \\
\text { subgroup: } 36.9 \pm 9.2\end{array}$ & $\begin{array}{l}92.1 \pm 52.4 \\
\text { pre-CrCl }<50 \\
\text { subgroup: } 60.1 \pm 35.5\end{array}$ & $110.5 \pm 56.8$ & & & $\begin{array}{l}\text { in patients on } \mathrm{IABP}^{6}, \mathrm{CrCl} \\
\text { increase from } 38.4 \pm 8.2 \text { to } \\
67.9 \pm 40.3\end{array}$ \\
\hline Sandner [16] & continuous & $\begin{array}{l}\mathrm{eGFR}^{2} \\
\mathrm{G}^{9}: 44.6 \pm 13.6 \\
\mathrm{G} 2: 76.7 \pm 12.5\end{array}$ & & $\begin{array}{l}\text { G1: } 80.7 \pm 32.6 \\
\text { G2: } 93.7 \pm 36.5\end{array}$ & G1: $70.9 \pm 21.9$ & G1: $62.7 \pm 25$ & $\begin{array}{l}65.3 \% \text { recovered } R^{1} \text { from } \\
\text { eGFR }<60 \text { to }>60 \text { at } 1 \text { month of } \\
\text { LVAD support }\end{array}$ \\
\hline
\end{tabular}

\footnotetext{
${ }^{1}$ Renal function. ${ }^{2}$ Estimated GFR $\left(\mathrm{ml} / \mathrm{min} / 1.73 \mathrm{~m}^{2}\right)$ calculated by Modification of Diet in Renal Disease equation. ${ }^{3}$ Blood urea nitrogen (mg/dl). ${ }^{4}$ Serum creatinine $(\mathrm{mg} / \mathrm{dl}) .{ }^{5} \mathrm{CrCl}=$ creatinine clearance $(\mathrm{ml} / \mathrm{min})$ calculated by Cockcroft-Gault formula. ${ }^{6}$ Intra-aortic balloon pump. ${ }^{7} \mathrm{Creatinine} \mathrm{clearance}(\mathrm{ml} /$ $\mathrm{min} / 1.73 \mathrm{~m}^{2}$ ) calculated by the MDRD formula. ${ }^{8} \mathrm{O}=$ overall; $\mathrm{G} 1=$ group $1 \mathrm{CrCl}<45 ; \mathrm{G} 2=$ group $2 \mathrm{CrCl} 45-65 ; \mathrm{G} 3=\operatorname{group} 3 \mathrm{CrCl}>65 .{ }^{9} \mathrm{G} 1=\mathrm{eGFR}<60$ at baseline; $\mathrm{G} 2=\mathrm{eGFR}>60$ at baseline.
}

versus pulsatile-flow devices [8]. The incidence of ARF necessitating RRT ranges from 14 to $32.5 \%[11,54,55]$ and remains a serious complication after LVAD implantation. The occurrence of ARF confers significant morbidity and mortality $[11,54]$.

Preoperative renal function, especially with $\mathrm{sCr}>1.5$ $\mathrm{mg} / \mathrm{dl}$, was reported to predict postimplantation AKI and length of ICU stay [40]. However, in this study the mean baseline sCr level was only slightly higher in the group that developed ARF or was comparable between ARF and NO-ARF groups, suggesting that RD before implantation may not be the best predictor of postoperative ARF [10-12].

Patients with ARF had a higher central venous pressure and a lower left ventricular end-diastolic dimension before LVAD implantation, indicating worse right ventricular function before the LVAD implantation [12]. In addition, Alba et al. [10] demonstrated that longer cardiopulmonary bypass $(\mathrm{CPB})$ time, higher intraoperative blood loss, and reoperation were associated risk factors for the development of AKI. Finally, Topkara et al. [11] showed that patients who had post- operative renal failure requiring RRT were older (53.7 \pm 12.9 vs. $48.2 \pm 14.2$ years, $\mathrm{p}=0.009$ ), had a higher incidence of IABP use ( 46.6 vs. $26.2 \%, p=0.006)$, with a higher preoperative mean LVAD score $(5.8 \pm 3.5$ vs. $3.8 \pm 3.3, \mathrm{p}=0.001)$ and a lower mean total protein and albumin levels $(\mathrm{g} / \mathrm{dl})(5.8 \pm 1.4$ vs. $6.4 \pm 1.2, \mathrm{p}=$ 0.007 , and $3.3 \pm 0.6$ vs. $3.6 \pm 0.6, p=0.009$, respectively) than those without renal failure. Overall, patient risk parameters including increased age, lower output states, right ventricular dysfunction, malnutrition, and multisystem comorbid conditions have been identified as continuous risk factors for the development of AKI after LVAD implantation. Additionally, surgical risk factors include prolonged CPB time, blood loss, and reoperation.

ARF after LVAD implantation has been identified as a negative predictor of outcome $[11,56]$ and has been highly associated with the development of several complications and high mortality $[10,11]$. Patients with postLVAD renal failure had a significantly lower post-LVAD survival regardless of pre-LVAD renal function $(\mathrm{p}<$ $0.001)[10,16]$. Genovese et al. [52] found among 14 ear- 
Table 2. Incidence and outcome of AKI after implantation of LVAD

\begin{tabular}{|c|c|c|c|c|}
\hline $\begin{array}{l}\text { Reference } \\
\text { (first author) }\end{array}$ & LVAD type & Incidence & Outcome & Diagnosis criteria \\
\hline Borgi [12] & continuous & $28 / 100(28 \%)$ & $\begin{array}{l}\text { longer hospital stay ( } 32.4 \text { vs. } 18.7 ; \mathrm{p}=0.05) \text {; more right ventricular failure } \\
(25 \text { vs. } 5.6 \% ; \mathrm{p}=0.01) \text { and VDRF* }(28.6 \text { vs. } 6.9 \% ; \mathrm{p}=0.007) \text {; higher } 30 \text {-day } \\
(17.9 \text { vs. } 0 \% ; \mathrm{p}<0.001), 180 \text {-day }(28.6 \text { vs. } 2.8 \% ; \mathrm{p}<0.001) \text {, and } 360 \text {-day } \\
\text { mortality }(28.6 \text { vs. } 6.9 \% ; \mathrm{p}=0.012) .68 \%(17 / 28) \text { returned to baseline } \\
\text { (preoperative level) within } 2 \text { weeks }\end{array}$ & $\begin{array}{l}\text { ARF: GFR decrease } \\
>50 \% \text { or doubling of } \\
\text { the creatinine level }\end{array}$ \\
\hline Topkara [11] & pulsatile & $65 / 201(32.3 \%)$ & $\begin{array}{l}\text { higher sepsis rate ( } 33.3 \text { vs. } 6.9 \%) \text {; lower bridge-to-transplantation rate }(52.4 \\
\text { vs. } 83.5 \%) \text {; lower post-LVAD survival rates at } 1 \text { year }(43.2 \text { vs. } 79.2 \%), 3 \text { years } \\
\text { ( } 39.1 \text { vs. } 74 \%), 5 \text { years ( } 34.7 \text { vs. } 68.3 \%), 7 \text { years ( } 34.7 \text { vs. } 66.4 \%) \text {, all p }<0.001\end{array}$ & $\begin{array}{l}\text { need postoperative } \\
\text { CVVHD* }\end{array}$ \\
\hline
\end{tabular}

${ }^{*} \mathrm{VDRF}=$ Ventilator-dependent respiratory failure; ${ }^{*} \mathrm{RIFLE}=$ risk, injury, failure, loss of renal function and end-stage kidney disease $;{ }^{*} \mathrm{CVVHD}=$ continuous veno-venous hemodialysis.

ly major adverse events during LVAD support, renal failure was the only one significantly associated with later mortality, which conferred a three-fold increased risk of 1-year mortality. Borgi et al. [12] also demonstrated that the development of postoperative ARF, especially requiring RRT, was a strong predictor of mortality (hazard ratio 4.59), not only in the postoperative period, but also at the 180- and 360-day intervals. In the case of postoperative ARF necessitating RRT, mortality rates were reported in 6 months of $93-100 \%[54,57]$. However, for cardiac recovery patients, the impact of ARF on survival was marginally significant $(p=0.05)$ [54]. Moreover, once patients recovered from ARF and survived to transplantation, survival was similar between groups with or without postimplantation ARF [11].

Not surprisingly, postoperative ARF has been associated with a higher incidence of postoperative right ventricular failure and ventricular arrhythmias [10]. Profound right ventricular failure contributes to decreased renal arterial blood flow, and urine volume, and subsequent progressive deterioration in renal function [58]. In this case, an early right ventricular assist device may be an indication to improve renal perfusion and renal function. By decreasing right-sided filling pressure, a right ventricular assist device can provide a more favorable arteriovenous pressure gradient across the kidney.
In addition, postoperative ARF has been reported to be related to a significantly lower rate of CTX $[11,54]$ and to a higher rate of sepsis [11], as well as a higher incidence of infections and liver injury [10]. In contrast, Demirozu et al. [55] have reported more favorable outcomes in 15 patients requiring postimplant RRT, 10 of which had improved renal function and were withdrawn from RRT in 2 months. Of these 10 patients, 3 underwent heart transplantation and 5 awaited heart transplantation with good quality of life.

Renal failure can significantly increase resource utilization. Several studies have questioned the cost-effectiveness of LVAD therapy $[59,60]$. Nevertheless, with appropriate patient selection, longer-term benefits, such as improved renal function, can outweigh short-term morbidity [61]. Preoperative evaluation to minimize risk factors, as well as perioperative optimization of hemodynamics, are of utmost importance to prevent the complication of AKI after LVAD implantation.

\section{Conclusion}

LVAD implantation restores cardiac output, improves hemodynamics, and allows for mechanical unloading which positively impacts systemic and biochemical re- 
sponses. The effect of LVAD support on renal function is complex and patient criteria for LVAD implantation remain one of the most difficult, critical and challenging issues. Major impairment of renal function preoperatively clearly indicates a relatively poor prognosis after LVAD implantation, and should therefore be considered at least a relative contraindication to LVAD implantation. Known risk factors such as age, right ventricular dysfunction, malnutrition, multisystem comorbid conditions, and intraoperative blood loss importantly affect outcomes with this lifesaving device. Careful assessment of kidney length, sCr, and estimated GFR can assist with the prediction of reversibility of $\mathrm{RD}$. Specific parameters include $\mathrm{sCr}<3 \mathrm{mg} / \mathrm{dl}$, improved GFR response to optimal medical therapy, and kidney length $>10 \mathrm{~cm}$. Early LVAD implantation, with the resulting improvement in renal perfusion, reduces postoperative AKI and leads to improved long-term renal function and overall improved outcomes. The use of LVAD-supportive technology has the potential to convert a proportion of transplant-ineli- gible patients into acceptable transplant candidates, by providing a beneficial effect on end-organ function, including recovery of renal function $[9,62,63]$. Further studies are needed to aid in identifying patients best suited to benefit from this technology and to refine the therapy to reduce associated risks.

\section{Acknowledgements}

The study was supported in part by research grants from the National Science \& Technology Pillar Program during the Twelfth Five-Year Plan Period, China (2011BAI10B00), JiangSu Government Scholarship for Overseas Studies, China (JS-2010-127) and Medical Scientific Research Foundation of Jiangsu Province, China (Z201002).

\section{Disclosure Statement}

The authors have no conflicts of interest to disclose.

\section{References}

1 Roger VL, Weston SA, Redfield MM, Hellermann-Homan JP, Killian J, Yawn BP, Jacobsen SJ: Trends in heart failure incidence and survival in a community-based population. JAMA 2004;292:344-350.

-2 Rose EA, Gelijns AC, Moskowitz AJ, Heitjan DF, Stevenson LW, Dembitsky W, Long JW, Ascheim DD, Tierney AR, Levitan RG, Watson JT, Meier P, Ronan NS, Shapiro PA, Lazar RM, Miller LW, Gupta L, Frazier $\mathrm{OH}$, Desvigne-Nickens $\mathrm{P}, \mathrm{Oz} \mathrm{MC}$, Poirier VL, Randomized Evaluation of Mechanical Assistance for the Treatment of Congestive Heart Failure Study G: Long-term use of a left ventricular assist device for end-stage heart failure. N Engl J Med 2001;345:14351443.

-3 Slaughter MS, Rogers JG, Milano CA, Russell SD, Conte JV, Feldman D, Sun B, Tatooles AJ, Delgado RM 3rd, Long JW, Wozniak TC, Ghumman W, Farrar DJ, Frazier OH: HeartMate II Investigators: advanced heart failure treated with continuous-flow left ventricular assist device. N Engl J Med 2009;361:22412251.

4 Cruz DN, Schmidt-Ott KM, Vescovo G, House AA, Kellum JA, Ronco C, McCullough PA: Pathophysiology of cardiorenal syndrome type 2 in stable chronic heart failure: workgroup statements from the eleventh consensus conference of the Acute Dialysis Quality Initiative (ADQI). Contrib Nephrol. Basel, Karger, 2013, vol 182, pp 117-136.

5 Mao H, Giuliani A, Blanca-Martos L, Kim JC, Nayak A, Virzi G, Brocca A, Scalzotto E, Neri
M, Katz N, Ronco C: Effect of percutaneous ventricular assist devices on renal function. Blood Purif 2013;35:119-266.

-6 Hasin T, Topilsky Y, Schirger JA, Li Z, Zhao Y, Boilson BA, Clavell AL, Rodeheffer RJ, Frantz RP, Edwards BS, Pereira NL, Joyce L, Daly R, Park SJ, Kushwaha SS: Changes in renal function after implantation of continuous-flow left ventricular assist devices. J Am Coll Cardiol 2012;59:2636.

$\checkmark 7$ Russell SD, Rogers JG, Milano CA, Dyke DB, Pagani FD, Aranda JM, Klodell CT Jr, Boyle AJ, John R, Chen L, Massey HT, Farrar DJ, Conte JV; HeartMate II Clinical Investigators: Renal and hepatic function improve in advanced heart failure patients during continuous-flow support with the HeartMate II left ventricular assist device. Circulation 2009; 120:2352-2357.

-8 Sandner SE, Zimpfer D, Zrunek P, Dunkler D, Schima H, Rajek A, Grimm M, Wolner E, Wieselthaler GM: Renal function after implantation of continuous-versus pulsatile-flow left ventricular assist devices. J Heart Lung Transplant 2008;27:469-473.

-9 Butler J, Geisberg C, Howser R, Portner PM, Rogers JG, Deng MC, Pierson RN 3rd: Relationship between renal function and left ventricular assist device use. Ann Thorac Surg 2006;81:1745-1751.

10 Alba AC, Rao V, Ivanov J, Ross HJ, Delgado DH: Predictors of acute renal dysfunction after ventricular assist device placement. J Card Fail 2009;15:874-881.
11 Topkara VK, Dang NC, Barili F, Cheema FH, Martens TP, George I, Bardakci H, Oz MC, Naka Y: Predictors and outcomes of continuous veno-venous hemodialysis use after implantation of a left ventricular assist device. J Heart Lung Transplant 2006;25:404408 .

12 Borgi J, Tsiouris A, Hodari A, Cogan CM, Paone G, Morgan JA: Significance of postoperative acute renal failure after continuous-flow left ventricular assist device implantation. Ann Thorac Surg 2013;95:163169.

13 Lietz K, Miller LW: Patient selection for leftventricular assist devices. Curr Opin Cardiol 2009;24:246-251.

14 Lund LH, Matthews J, Aaronson K: Patient selection for left ventricular assist devices. Eur J Heart Fail 2010;12:434-443.

15 James KB, McCarthy PM, Jaalouk S, Bravo EL, Betkowski A, Thomas JD, Nakatani S, Fouad-Tarazi FM: Plasma volume and its regulatory factors in congestive heart failure after implantation of long-term left ventricular assist devices. Circulation 1996;93:1515-1519.

-16 Sandner SE, Zimpfer D, Zrunek P, Rajek A, Schima H, Dunkler D, Grimm M, Wolner E, Wieselthaler GM: Renal function and outcome after continuous flow left ventricular assist device implantation. Ann Thorac Surg 2009;87:1072-1078.

17 Givertz MM: Cardiology patient pages: Ventricular assist devices. Important information for patients and families. Circulation 2011; 124:e305-e311. 
18 Lietz K, Miller LW: Left ventricular assist devices: evolving devices and indications for use in ischemic heart disease. Curr Opin Cardiol 2004;19:613-618.

19 Vural KM: Ventricular assist device applications. Anadolu Kardiyol Derg 2008;8(suppl 2): 117-130.

20 Wakisaka Y, Taenaka Y, Chikanari K, Nakatani T, Tatsumi E, Masuzawa T, Nishimura T, Takewa Y, Ohno T, Takano H: Long-term evaluation of a nonpulsatile mechanical circulatory support system. Artif Organs 1997; 21:639-644.

-21 Travis AR, Giridharan GA, Pantalos GM, Dowling RD, Prabhu SD, Slaughter MS, Sobieski M, Undar A, Farrar DJ, Koenig SC: Vascular pulsatility in patients with a pulsatile- or continuous-flow ventricular assist device. J Thorac Cardiovasc Surg 2007;133:517524.

-22 Amir O, Radovancevic B, Delgado RM 3rd, Kar B, Radovancevic R, Henderson M, Cohn WE, Smart FW: Peripheral vascular reactivity in patients with pulsatile vs. axial flow left ventricular assist device support. J Heart Lung Transplant 2006;25:391-394.

-23 James KB, McCarthy PM, Thomas JD, Vargo R, Hobbs RE, Sapp S, Bravo E: Effect of the implantable left ventricular assist device on neuroendocrine activation in heart failure. Circulation 1995;92:II191-II195.

24 Yambe T: Experimental study of renal sympathetic nerve activity during left ventricular assist device pumping. Sci Rep Res Inst Tohoku Univ Med 1990;37:1-9.

-25 Saito S, Westaby S, Piggot D, Dudnikov S, Robson D, Catarino PA, Clelland C, Nojiri C: End-organ function during chronic nonpulsatile circulation. Ann Thorac Surg 2002;74 1080-1085.

26 Nakano T, Tominaga R, Morita S, Masuda M, Nagano I, Imasaka K, Yasui H: Impacts of pulsatile systemic circulation on endothelium-derived nitric oxide release in anesthetized dogs. Ann Thorac Surg 2001;72:156162.

27 Bock JS, Gottlieb SS: Cardiorenal syndrome: new perspectives. Circulation 2010;121: 2592-2600.

28 Sezai A, Shiono M, Orime Y, Nakata K, Hata M, Yamada H, Iida M, Kashiwazaki S, Kinishita J, Nemoto M, Koujima T, Sezai Y, Saitoh T: Renal circulation and cellular metabolism during left ventricular assisted circulation: comparison study of pulsatile and nonpulsatile assists. Artif Organs 1997;21: 830-835.

29 Nemoto M: Experimental evaluation of the influence of complete artificial circulation on renal circulation and tissue metabolism comparative study of pulsatile vs. nonpulsatile circulation. Ann Thorac Cardiovasc Surg 2003;9:355-364.

-30 Iwashima Y, Yanase M, Horio T, Seguchi O, Murata Y, Fujita T, Toda K, Kawano Y, Nakatani T: Effect of pulsatile left ventricular assist system implantation on Doppler measure- ments of renal hemodynamics in patients with advanced heart failure. Artif Organs 2012;36:353-358.

-31 Ootaki C, Yamashita M, Ootaki Y, Kamohara K, Weber S, Klatte RS, Smith WA, Massiello AL, Emancipator SN, Golding LA, Fukamachi K: Reduced pulsatility induces periarteritis in kidney: role of the local renin-angiotensin system. J Thorac Cardiovasc Surg 2008; 136:150-158

32 Yambe T, Nitta S, Katahira Y, Sonobe T, Naganuma S, Akiho H, Chiba S, Kakinuma Y, Hayashi $\mathrm{H}$, Tanaka M: Postganglionic sympathetic nerve activity with correlation to heart rhythm during left ventricular assistance. Artif Organs 1991;15:212-217.

- 33 Yambe T, Nitta S, Katahira Y, Sonobe T, Tanaka M, Miura M, Satoh N, Mohri H, Yoshizawa $M$, Takeda $\mathrm{H}$ : Effect of left ventricular assistance on sympathetic tone. Int J Artif Organs 1990;13:681-686.

34 Yambe T, Nitta S, Katahira Y, Sonobe T, Naganuma S, Akiho H, Chiba S, Kakinuma Y, Hayashi H, Izutsu K: Cardiac-related sympathetic nerve activity during circulation with only the left ventricular assist device. Int $\mathrm{J} \mathrm{Ar}$ tif Organs 1992;15:49-54.

35 Nitta S, Yambe T, Katahira Y, Sonobe T, Naganuma S, Kakinuma Y, Tanaka M, Miura M, Sato N, Mohri H: Sympathetic nerve activity during maintaining circulation with only left ventricular assist device. Sci Rep Res Inst Tohoku Univ Med 1991;38:51-56.

-36 Nishimura T, Tatsumi E, Taenaka Y, Nishinaka T, Nakatani T, Masuzawa T, Nakata $M$, Nakamura M, Endo S, Takano H: Effects of long-term nonpulsatile left heart bypass on the mechanical properties of the aortic wall. ASAIO J 1999;45:455-459.

37 Kihara S, Litwak KN, Nichols L, Litwak P, Kameneva MV, Wu Z, Kormos RL, Griffith BP: Smooth muscle cell hypertrophy of renal cortex arteries with chronic continuous flow left ventricular assist. Ann Thorac Surg 2003;75: 178-183; discussion 183

38 Yamagishi T, Oshima K, Hasegawa Y, Mohara J, Kanda T, Ishikawa S, Morishita Y: Cytokine induction by LVAD in the canine kidney. J Cardiovasc Surg (Torino) 2001;42:759-768.

39 Yoshioka D, Sakaguchi T, Saito S, Miyagawa S, Nishi H, Yoshikawa Y, Fukushima S, Saito T, Daimon T, Ueno T, Kuratani T, Sawa Y: Predictor of early mortality for severe heart failure patients with left ventricular assist device implantation: significance of INTERMACS level and renal function. Circ J 2012;76:1631-1638.

40 Ma L, Fujino Y, Matsumiya G, Sawa Y, Mashimo T: Renal function with left ventricular assist devices: the poorer the preoperative renal function, the longer the recovery. Med Sci Monit 2008; 14:CR621-CR627.

$\checkmark 41$ Alba AC, Rao V, Ivanov J, Ross HJ, Delgado DH: Usefulness of the INTERMACS scale to predict outcomes after mechanical assist device implantation. J Heart Lung Transplant 2009;28:827-833.
42 Boyle AJ, Ascheim DD, Russo MJ, Kormos RL, John R, Naka Y, Gelijns AC, Hong KN, Teuteberg JJ: Clinical outcomes for continuous-flow left ventricular assist device patients stratified by pre-operative INTERMACS classification. J Heart Lung Transplant 2011;30: 402-407.

43 Singh M, Shullo M, Kormos RL, Lockard K, Zomak R, Simon MA, Bermudez C, Bhama J, McNamara D, Toyoda Y, Teuteberg JJ: Impact of renal function before mechanical circulatory support on posttransplant renal outcomes. Ann Thorac Surg 2011;91:1348-1354.

44 Kirklin JK, Naftel DC, Kormos RL, Stevenson LW, Pagani FD, Miller MA, Ulisney KL, Baldwin JT, Young JB: Third INTERMACS annual report: the evolution of destination therapy in the United States. J Heart Lung Transplant 2011;30:115-123.

45 Khot UN, Mishra M, Yamani MH, Smedira NG, Paganini E, Yeager M, Buda T, McCarthy PM, Young JB, Starling RC: Severe renal dysfunction complicating cardiogenic shock is not a contraindication to mechanical support as a bridge to cardiac transplantation. J Am Coll Cardiol 2003;41:381-385.

- 46 Heywood JT, Fonarow GC, Costanzo MR Mathur VS, Wigneswaran JR, Wynne J, Committee ASA, Investigators: High prevalence of renal dysfunction and its impact on outcome in 118,465 patients hospitalized with acute decompensated heart failure: a report from the adhere database. J Card Fail 2007;13:422-430.

47 McAlister FA, Ezekowitz J, Tonelli M, Armstrong PW: Renal insufficiency and heart failure: prognostic and therapeutic implications from a prospective cohort study. Circulation 2004;109:1004-1009.

- 48 Nohria A, Hasselblad V, Stebbins A, Pauly DF, Fonarow GC, Shah M, Yancy CW, Califf RM, Stevenson LW, Hill JA: Cardiorenal interactions: insights from the escape trial. J Am Coll Cardiol 2008;51:1268-1274.

-49 Kamdar F, Boyle A, Liao K, Colvin-Adams M, Joyce L, John R: Effects of centrifugal, axial, and pulsatile left ventricular assist device support on end-organ function in heart failure patients. J Heart Lung Transplant 2009;28: 352-359.

50 Imamura $\mathrm{T}$, Kinugawa K, Shiga T, Endo M, Kato N, Inaba T, Maki H, Hatano M, Yao A, Nishimura T, Hirata Y, Kyo S, Ono M, Nagai R: Preoperative levels of bilirubin or creatinine adjusted by age can predict their reversibility after implantation of left ventricular assist device. Circ J 2012;77:96-104.

-51 Yuan N, Arnaoutakis GJ, George TJ, Allen JG Ju DG, Schaffer JM, Russell SD, Shah AS, Conte JV: The spectrum of complications following left ventricular assist device placement. J Card Surg 2012;27:630-638.

52 Genovese EA, Dew MA, Teuteberg JJ, Simon MA, Bhama JK, Bermudez CA, Lockard KL, Winowich S, Kormos RL: Early adverse events as predictors of 1-year mortality during mechanical circulatory support. J Heart Lung Transplant 2010;29:981-988. 
53 Parascandola SA, Pae WE Jr, Davis PK, Miller CA, Pierce WS, Waldhausen JA: Determinants of survival in patients with ventricular assist devices. ASAIO Trans 1988;34:222-228.

54 Kaltenmaier B, Pommer W, Kaufmann F, Hennig E, Molzahn M, Hetzer R: Outcome of patients with ventricular assist devices and acute renal failure requiring renal replacement therapy. ASAIO J 2000;46:330-333.

55 Demirozu ZT, Etheridge WB, Radovancevic R, Frazier OH: Results of HeartMate II left ventricular assist device implantation on renal function in patients requiring post-implant renal replacement therapy. J Heart Lung Transplant 2011;30:182-187.

56 Daneshmand MA, Rajagopal K, Lima B, Khorram N, Blue LJ, Lodge AJ, Hernandez AF, Rogers JG, Milano CA: Left ventricular assist device destination therapy versus extended criteria cardiac transplant. Ann Thorac Surg 2010;89:1205-1209; discussion 1210.
Kanter KR, Swartz MT, Pennington DG, Ruzevich SA, Madden M, McBride LR, Termuhlen DF: Renal failure in patients with ventricular assist devices. ASAIO Trans 1987; 33:426-428.

58 Akamatsu H, Arai H, Sakamoto T, Suzuki A: Effects of right ventricular failure on renal function during pneumatic left ventricular assist. Artif Organs 1996;20:240-246.

59 Moreno SG, Novielli N, Cooper NJ: Cost-effectiveness of the implantable HeartMate II left ventricular assist device for patients awaiting heart transplantation. J Heart Lung Transplant 2012;31:450-458.
60 Hernandez AF, Shea AM, Milano CA, Rogers JG, Hammill BG, O'Connor CM, Schulman KA, Peterson ED, Curtis LH: Long-term outcomes and costs of ventricular assist devices among Medicare beneficiaries. JAMA 2008; 300:2398-2406.

61 Rajagopalan N, Hoopes CW: Renal failure following ventricular assist device placement. J Am Coll Cardiol 2012;59:2220, author reply p 2220.

62 Kainuma S, Sakaguchi T, Saito S, Miyagawa S, Yoshikawa Y, Yamauchi T, Sakata Y, Takahashi A, Uehata T, Kuratani T, Sawa Y: Implantation of a Jarvik 2000 left ventricular assist device as a bridge to eligibility for refractory heart failure with renal dysfunction. J Artif Organs 2012;15:83-86.

-63 Elhenawy AM, Algarni KD, Rodger M, Maciver J, Maganti M, Cusimano RJ, Yau TM, Delgado DH, Ross HJ, Rao V: Mechanical circulatory support as a bridge to transplant candidacy. J Card Surg 2011;26:542-547. 